\title{
Imagens de absorção: do cinema aos ambientes imersivos digitais
}

\author{
CESAR BAIO
}

\section{Resumo}

O texto passa em revista a produção artística em ambientes virtuais para examinar os regimes de imagem instituídos por aparatos como os de realidade virtual, as caves e os panoramas digitais. A hipótese que orienta as análises é que estes aparatos estabelecem o que poderia ser entendido como regimes de absorção, vinculando-se a uma herança estética platônica que esteve presente de diferentes maneiras ao longo da história da arte, abarcando o renascimento, os panoramas do século XVIII, a fotografia e, principalmente, o cinema. Para tanto, parte-se da filosofia de Vilém Flusser e dos teóricos dos ambientes imersivos e das narrativas hipertextuais.

Palavras-chave:

Teoria da imagem, imagem digital, realidade virtual 


\title{
Absorption's images: from cinema to digital immersive environments
}

\author{
CESAR BAIO
}

\section{Abstract}

The text reviews the artistic production of virtual environments to examine the regimes established by imaging devices such as virtual reality, caves and digitals panoramas. The hypothesis guiding the analysis is that these devices establish what could be understood as absorption regimes, linking to a Platonic aesthetic heritage that was present in different ways throughout art history, spanning the Renaissance, the panoramas of the century XVIII, Keywords: Image theory, digital imaging, virtual reality photography, and especially the cinema. To do so, we start from the philosophy Flusser and theorists of immersive environments and hypertextual narratives. 


\section{A virtualidade e a questão da imersão}

Entrar dentro do filme, atravessar a fronteira entre o atual e o virtual, passar para o lado de lá, escapar para dentro do universo de pura ficção do cinema, esse talvez tenha sido o sonho maior de toda a aventura cinematográfica, o sonho de um cinema permeável ao espectador, um cinema capaz de transformar o espectador em protagonista e mergulhá-lo inteiramente dentro da história (MACHADO, 2007, p.164).

Em Les carabiniers, de Jean Luc Godard, seduzido pela beleza da personagem vista na tela de cinema, Michelangelo procura a passagem que dá acesso ao lado de dentro do filme. Como notou Machado (2007), esta passagem do filme do diretor francês faz referência a um antigo filme chamado Uncle Josh - At The Moving Picture Show (1902), de Edwin S. Porter, produzido para a companhia de Thomas Edson. Trata-se de mais uma aventura da conhecida personagem da época, Uncle Josh, que vai ao cinema e tenta entrar na imagem para defender uma mulher em perigo. Este filme de Porter, por sua vez, faz referência também a outra passagem curiosa da história do cinema. A certa altura do filme, ao ver um trem se aproximar da tela, Josh foge e se protege, em uma alusão à famosa história narrada pela imprensa parisiense após a primeira exibição do filme dos irmãos Lumière'. Melhor sorte, no entanto, teve a personagem Cecília de The purple rose of Cairo que, seduzida pela história a que assistia na tela de cinema, encontrou um meio de atravessar para o lado de lá, passando a fazer parte dos acontecimentos da cena e contracenando com as personagens pelas quais havia sido atraída.

The purpure rose of Cairo e At The Moving Picture Show são exemplos interessantes de como o cinema tematizou o tão 
almejado sonho da imersão total. Esta que já tinha sido anteriormente o ideal do teatro ilusionista do século XVIII e que atualmente ganha contornos mais acentuados nos ambientes virtuais imersivos. Por meio destes dois exemplos é possível refletir sobre a natureza diversa de dois regimes de sentido que vêm sendo instaurados no campo da imagem digital e, assim, identificar uma fissura na própria fundação da idéia de imersão.

No caso dos ingênuos Josh e Michelangelo, assim como das hipotéticas vítimas do trem dos Lumière, percebe-se que eles não viam distinção entre o que era mostrado na imagem e o que estava de fato do seu lado. Josh acreditava estar na presença do corruptor da inocente mocinha do filme e foi isso que o levou a atacá-lo. Também Michelangelo estava certo de que a garota tomava mesmo banho à sua frente e estava acessível em um palco, tal qual o da sala do teatro.

Por outro lado, ainda que seduzida pela mágica fulgurante da imagem, Cecília não tinha esta inocência; ela sabia que o mundo que a fazia sonhar existia somente do lado de lá, em oposição ao seu próprio universo, e que, por isso, teria que atravessar a tela se quisesse viver as histórias daquele mundo. Assim como a Alice, de Lewis Carroll, ela cruzou os limites da sua realidade em busca de um mergulho nas aventuras impossíveis de serem vividas na concretude da realidade. Embora esta diferença à primeira vista pareça sutil, é justamente ela que instaura uma das mais profundas transformações que se desdobram dos aparatos técnicos contemporâneos, e que começam a deixar evidentes dois regimes de imagem fundamentalmente diferentes.

No primeiro deles, a imagem conduz ao mundo da imaginação, um universo outro, que existe em paralelo ao nosso; nele, a tela é uma janela pela qual atravessamos em busca de um lugar outro que não aquele do mundo da nossa experiência. No segundo regime de sentido, porém, a imagem se apresenta como uma presença concreta daquilo que vemos, de modo que não há diferenças entre o mundo da imagem e o do sujeito. No primeiro, a imagem leva à transcendência, fazendo com que nos desprendamos de nossos corpos para nos tornarmos uma instância de pura vidência; já no segundo, a cena se funde ao nosso mundo, finalmente reconciliando a experiência psíquica e a corporal. Enquanto no primeiro o quadro cinematográfico é uma janela, uma passagem mágica para um universo impossível, no segundo não existe quadro: aquele que vê e aquilo que é visto ocupam no mesmo lugar, têm o mesmo estatuto e fazem parte do mesmo evento. No 
primeiro, como um espelho de Alice, cada imagem se apresenta como universo paralelo, rumo ao qual somos lançados por seus aparatos, enquanto no segundo, a ingenuidade das personagens de Porter e Godard é substituída pela consciência da coexistência de múltiplas camadas de realidade que se imbricam, se contaminam e se deslocam. No primeiro, como observadores insaciáveis, nós somos absorvidos para o universo da imagem; no segundo, a imagem se projeta como objeto concreto rumo à nossa experiência e toca nosso corpo. Essas duas maneiras de compreender a imagem, porém, podem ser vistas como instrumentos teóricos capazes de auxiliar na análise da produção imagética atual. Este ensaio concentra-se na primeira delas, privilegiando o exame de trabalhos artísticos que se produzem como ambientes imersivos. A análise das suas dimensões epistemológicas, éticas e estéticas busca compreender como eles deslocam as relações entre sujeito e imagem, instituindo um modo de existência bastante específico para a imagem, que pode ser caracterizado por seu caráter absortivo.

\section{Programando espelhos de Alice}

Desde os anos 1980, no ritmo do desenvolvimento das tecnologias de vídeo e de projeção digitais, um número cada vez maior de artistas vem tentando tornar real o sonho do mergulho em realidades paralelas que foi imaginado em uma infinidade de filmes, livros e séries de TV. Esses trabalhos que dão forma à chamada Realidade Virtual levam à diante a idéia de aprimorar um regime de sentido fundado no que se pode entender como uma absorção do sujeito no universo interno da imagem. Com origem no Latim, o termo absorver é resultado da junção da preposição $a b$ (de) e do verbo sorbere (engolir). E, tal como definido pela língua portuguesa, absorver pode significar elevar-se, arrebatar-se, extasiar-se, mas também, sumir, perder-se ou deixar-se consumir, submergir, tragar, devorar, engolir. A palavra absorver conserva assim certa ambiguidade que é também característica desses regimes de sentido, que oscilam entre a transcendência e a devoração. De maneira geral, os regimes de absorção partem da proposta de atrair o observador que, extasiado, é arrebatado para dentro da imagem e submerge para o universo que se abre diante dos seus sentidos.

No campo da arte e tecnologia, o mergulho em um sonho virtual logo se popularizou e esteve presente em uma parte significativa da sua produção desde então. Muitos artistas 
que já trabalhavam com vídeo nos anos 1970 se juntaram a outros recém-chagados e a engenheiros e programadores para desenvolverem pesquisas sobre novas maneiras de imersão. Ao mesmo tempo, cresceu a quantidade de ensaios críticos e teorias que buscaram logo abarcar tais regimes de imersão em suas análises.

Entre os trabalhos teóricos mais sistemáticos desenvolvidos sobre este tema está o de Oliver Grau (2003), historiador do virtual que situa entre os pioneiros destas práticas nomes de artistas como Jeffrey Shaw, Monika Fleischemann, Wolfgang Strauss, Agnes Hegedues, Daniela Plewe, Maurice Benayoun e Michel Neimark. No Brasil, dentre os primeiros artistas a trabalharem neste campo, estão gente como André Parente, Rejane Cantoni e Daniela Kutschat. Como resultado de suas pesquisas estéticas, estes artistas acabaram por produzir obras em realidade virtual, cave e panoramas digitais. De maneira geral, tais projetos conservam a busca de um regime de imagem ainda mais imersivo que o do cinema. Esta mesma ambição de expansão do cinema motivou também muitos artistas a se voltarem às narrativas audiovisuais interativas, em instalações pioneiras como Lorna (1984), de Lynn Hershman, Frontiers of Utopia (1995), de Jill Scott e Portrait no 1 (1990), de Luc Courchesne. Embora algumas delas mantenham aspectos que as diferenciem das imagens imersivas, uma análise a partir da concepção de labirintos hipermidiáticos (LEÃO, 2005) revela que sua vocação hipertextual está profundamente associada à noção de imersão em um ambiente narrativo não-linear.

Tanto obras que trabalham a partir da noção de ambientes virtuais quanto as que desenvolvem narrativas audiovisuais interativas são baseadas em estratégias de deslocamento do sujeito para experiências em outros universos possíveis. Esta estética foi concebida pela teórica da mídia Söke Dinkla (2002), como the floating work of art, obras de arte que utilizam as tecnologias interativas para fazer o seu público navegar em espaços de experiência.

Os the floating work of art concebem o meio digital não como uma extensão dos órgãos sensoriais humanos, mas como um espaço estético, que habilita a reconstrução de uma forma modificada de mundo² (DINKLA, 2002, p.35).

Obras como estas buscam substituir o mundo dos objetos físicos por um mundo de textos e signos entre os quais o público é convidado a "flutuar" de maneira não-linear no fluxo 
dos braços narrativos que a ele se abrem. Muitos artistas utilizam esta metáfora para criar suas cosmologias particulares, por meio de espaços de som, imagem e texto, não hierárquicos, nos quais cabe ao sujeito traçar seu próprio caminho.

Na mesma medida em que estes trabalhos mantinham em seu horizonte o ideal de lançar o sujeito no mundo da imagem de um modo ainda mais profundo do que o cinema, as interfaces interativas mostraram-se ao artista como o campo mais propício para a elaboração de imagens ainda mais imersivas. Essas interfaces passam, assim, a serem tomadas como instrumentos poderosos para a navegação em meio ao espaço virtual.

Memory Theater VR (1997), de Agnes Hegedues, por exemplo, é um ambiente virtual vinculado à linha de pesquisa surgida no início das interfaces computacionais. Tais abordagens rejeitam o desktop como metáfora e procuram por interfaces baseadas em visualizações espaciais geradas de forma dinâmica (GRAU, 2003). Formada por uma rotunda panorâmica, a tela demarca os limites do ambiente de realidade virtual criado pela artista, formando algo como um teatro virtual. No centro deste espaço existe um mouse 3-D ligado ao sistema, de modo que a imagem panorâmica responda em tempo real (algo difícil de se realizar com a capacidade de processamento daquela época), possibilitando a navegação no espaço virtual.

O trabalho remete aos teatros da memória do Renascimento. Construídos como templos do saber, estes lugares eram consagrados ao pensamento e visavam ao armazenamento da memória que pudesse representar o conjunto de conhecimentos de seu tempo. Usados como facilitadores nos processos de criação da época, esses templos eram concebidos como espaços mentais nos quais era possível colocar o espírito para "navegar" e articular combinações entre os diversos elementos significantes.

Em Memory Theater VR, o espaço se abre como uma coleção de ambientes que leva o visitante para um passeio pela história da arte e da mídia. O visitante se locomove nesse espaço narrativo usando o mouse, com o qual ele pode navegar por entre suas salas, fazendo suas próprias conexões entre as coisas que lhe chame atenção, passando de um espaço a outro e retornando aos seus pontos de interesse. Desse modo, a instalação estimula a experiência intelectual de associações entre as diferentes referências estéticas que, tomadas como citações históricas, permitem uma reflexão sobre o estágio atual da cultura.

Partindo de uma outra abordagem do espaço, o projeto OP-ERA, das artistas Rejane Cantoni e Daniela Kutschat, 
começou a ser desenvolvido em 1999 e assume como objetivo repensar os modelos espaciais da ciência e da arte. A partir desta proposta, as artistas brasileiras desenvolveram uma série de obras imersivas que buscam estabelecer uma relação simbiótica entre o corpo de participante e ambientes interativos que colocam em crise o modo como compreendemos o espaço. Bastante apoiadas em uma relação sensorial com a imagem, estas instalações demandam a ação do corpo do participante, a quem cabe geralmente explorar os espaços constituídos pelas artistas através de gráficos ou luzes. As estratégias para a criação destes ambientes são diversas. Em OP_ERA: Sonic Dimension (2005), as paredes de uma sala escura recebem a projeção de linhas verticais que remetem a cordas. Quantos estas linhas de luz são tocadas, elas vibram de acordo com uma determinada frequência. Já em OP_ERA: Haptic Interface (2004), uma luva de dados (dataglove) e um sistema de projeção de imagens estereoscópicas permite ao participante ver e manipular gráficos gerados por algoritmos baseados nos atratores de Edward Lorenz, que descrevem a evolução de um tipo específico de sistema complexo dinâmico no tempo e no espaço.

OP_ERA: Haptic Interface coloca em operação um modo de construção da imersão similar ao da Realidade Virtual, utilizada também em trabalhos como The Home of the Brain - Stoa of Berlin (1991), de Monika Fleischemann e Wolfgang Strauss. Neste caso, a interface é constituída de uma luva de dados e de um capacete de visualização em três dimensões (Head Mounted Display). A interatividade é então construída por meio da luva que capta os movimentos da mão e os transfere para uma mão virtual. Diferentemente do dispositivo cinematográfico, que é configurado como uma experiência coletiva, instalações como esta comportam apenas um único visitante por vez. Outras pessoas que por ventura estejam na mesma sala podem ver as imagens sem, no entanto, interagir com os objetos gráficos.

Outro artista que tem trabalhado sistematicamente na busca pela expansão da capacidade de imersão herdada do cinema é Jeffrey Shaw. Desde seus primeiros trabalhos, Shaw se colocou rumo à intensificação do engajamento do observador no universo narrativo da imagem, com obras como Legible City (1989), ConFiguring the Cave (1996) e Place Ruhr (2000).

A instalação Place Ruhr, em que o visitante é inserido em um ambiente a ser explorado segundo seu próprio interesse, atualiza questões presentes em toda a obra de Shaw. O trabalho é formado por uma grande tela de 360 graus que recebe as imagens geradas por um único projetor, localizado em uma 
plataforma giratória posicionada no centro de um espaço circular. Nesta plataforma, existe uma câmera-joystick que é o instrumento de interfaceamento entre público e imagem. Ao operar a câmera, o público passa a explorar o ambiente virtual; os botões de zoom estão ligados aos movimentos de avançar e retroceder a posição do ponto de vista no espaço informacional, permitindo o controle do tamanho do quadro, enquanto o movimento de pan (o giro horizontal da câmera no seu próprio eixo) faz girar a plataforma e o ponto de vista da imagem, deslocando também a posição da projeção na tela. Construído em $3 \mathrm{D}$ o ambiente virtual é composto por onze cilindros, sendo cada um deles uma imagem panorâmica, anteriormente filmada por um equipamento especial, em locais determinados da região de Ruhr, na Alemanha. Ao observador cabe comandar a câmera para se movimentar nesse mundo virtual, deslocando-se entre o interior desses panoramas.

Assim como outros trabalhos de Shaw, Place Ruhr remete aos panoramas que se difundiram no século XVIII, uma referência compartilhada pelo brasileiro André Parente, que desde 1999 tem trabalhado do desenvolvimento de seu Visorama. O sistema criado pelo artista, em parceria com o matemático Luiz Velho, consiste em um conjunto de hardware e software em forma de um binóculo, criado especialmente para permitir ao participante observar e interagir com imagens que cobrem trezentos e sessenta graus. O sistema foi utilizado em diferentes proposições artísticas, tendo sido exibido na $2^{\underline{a}}$ Mostra Petrobrás de Realidade Virtual (1999), na exposição Paisagem Carioca (2000) e, mais recentemente, em diversos museus e galerias ao dar corpo ao trabalho Figuras na Paisagem (2010).

Nos trabalhos de Shaw e Parente, a noção de estar dentro da imagem é criada pela arquitetura panorâmica da obra, que posiciona o observador como principal operador do percurso do seu próprio olhar. Ao interagir com estas aparatos de imersão, o participante é deslocado para uma experiência de tempo e de espaço inscrita unicamente no universo interno do virtual.

\section{Deslocando o lugar do sujeito}

Uma análise estética que relacione estas obras com o cinema pode revelar uma considerável mudança nas estratégias de cooptação do sujeito pelo dispositivo ${ }^{3}$. No cinema, a experiência proporcionada ao se assistir a um filme envolve o processamento de uma série de informações pelo corpo do espectador. Não apenas o sistema ocular como também o cérebro e por 
extensão todas as partes do corpo, estão implicados de alguma maneira na experiência proporcionada na sala de cinema. Por outro lado, o corpo do espectador de cinema permanece bem acomodado em sua cadeira e o agenciamento entre imagem e sujeito é feito pela chamada instância enunciativa do filme. Dada a condição de observador, é esta instância a responsável por enunciar ${ }^{4}$ os eventos da história, organizando-os de maneira hierárquica e, assim, determinando o modo como a narrativa é construída. Trata-se de um trabalho minucioso que poderia ser entendido como um tipo de design de informação, que se dá não apenas pela forma de organização dos fatos da história, mas também por meio da operação de todo o aparato cinematográfico envolvendo áreas diversas, tais como as de fotografia, montagem e som. Ainda que os processos mentais de cada pessoa levem a conclusões individuais, é esta instância enunciativa que agencia formalmente a narrativa, conduzindo todos os presentes na sala de cinema de uma maneira única pela história.

Em contrapartida, se for possível estabelecer um papel reservado ao sujeito nos ambientes imersivos, este é justamente o da instância enunciativa cinematográfica, ou, pelo menos, de uma parte dela. Isso porque o visitante pode não interferir necessariamente nas cenas da história, mas, ao se deslocar pelo ambiente, ele tece uma linha narrativa individual, "não bívia" (LEÃO, 2005, p.131), composta por uma paisagem que ele próprio faz entrecruzar.

Nessas interfaces, a interação entre sujeito e imagem pode ser assim resumida ao agenciamento de sentido que se dá entre o olhar do sujeito e o universo interno da história/imagem. Essa interação, no entanto, desacomoda o corpo da poltrona para investir em novos modos de engajamento. Em geral, o que tais interfaces tem em comum é a negação do tradicional conjunto teclado-mouse e a demanda do envolvimento corporal do sujeito. Uma vez chamado a se deslocar no espaço, em geral, o espectador precisa se manifestar fisicamente por meio da operação dos controles de navegação seja um joystick, uma luva de dados ou qualquer outro elemento usado como controlador da interface.

\section{O corpo como agenciador do olhar}

Para Mark Hansen, ao requisitar a atuação corporal do observador para comandar o olhar sobre a paisagem na tela, obras como as de Jeffrey Shaw estariam rompendo com a predominância da visualidade a favor de uma relação corporal entre o 
sujeito e a imagem. Hansen afirma que a artemídia contemporânea desloca o sistema perceptivo da visão para o corpo. Segundo sua tese, os trabalhos de Shaw podem ser tomados como “(...) a passagem de uma estética ocularcentrista dominante a uma estética háptica enraizada na afetividade corporificada"5 (HANSEN, 2004, p.12).

Embora as teorias de Hansen sejam inspiradoras, elas parecem servir mais para a elaboração de um horizonte almejado de possibilidades do que efetivamente para a análise de obras como as de Shaw. Ainda que estes trabalhos demandem uma outra resposta corporal do seu público em relação àquela imposta pelo cinema, é preciso questionar se esta resposta ainda não estaria centrada em uma pulsão predominantemente visual. Ao falar sobre seu trabalho, o próprio artista já aponta para outra direção: “(...) Place Ruhr obriga-o [o observador] a abandonar sua relação corporal com o espaço real em redor e entrar no espaço ficcional que o trabalho oferece (...)" (SHAW, 2002, p.273). E, de fato, é isso que acontece com quem visita a instalação. De uma maneira inconsciente, depois que os observadores descem da plataforma giratória, eles percebem que tem de se relocalizar no espaço real, como afirmaram algumas pessoas que passaram pela experiência (SHAW, 2002).

Se for verdade que nas obras de floating work of art o sujeito é posicionado de tal maneira que seu corpo é chamado a operar fisicamente os comandos de uma interface interativa, é preciso considerar também que toda esta operação ainda se dá a favor de uma exploração que é da ordem da observação. Desse modo, mesmo que o corpo esteja envolvido ativamente na experiência, estes ambientes ainda são de caráter predominantemente visual e textual.

Ao analisar Place Ruhr, por exemplo, é necessário se perguntar se os agenciamentos corporais habilitados pelos instrumentos de comando da interface estariam sendo colocados a favor de uma experiência verdadeiramente corporal ou se o que eles estariam fazendo seria somente operar um processo de mediação voltado predominantemente à visualidade. Uma análise sob tal perspectiva revela que no trabalho de Shaw, apesar de existir uma vinculação direta entre o corpo do público e o olhar da câmera virtual, uma vez que os movimentos no mundo físico estão orientados exclusivamente para a experiência da observação das cenas panorâmicas, a atuação corporal é demasiadamente tímida e está integralmente colocada a serviço do predomínio do interesse de ver. O que fica explícito, é o lugar que o corpo passa a ocupar como um agenciador do olhar. 
É possível ter uma evidência empírica disso quando se atenta para o fato de que, em Place Ruhr, existe um microfone junto à câmera, que é assim posicionado para captar o som emitido pelo observador e disparar palavras e sentenças tridimensionais no centro da tela. Fato curioso é que, ao observar a participação do público na instalação, constata-se que são raros os casos em que a pessoa que está no comando da câmera-joystick emite algum som. Quando isso acontece, na maior parte dos casos, trata-se de uma ação acidental. Nada existe na imagem que convide o público a se relacionar com ela por meio de sons ou a fazer qualquer movimento corporal que não esteja alinhado com seu desejo de visualidade. A dimensão visual é tão poderosa e a absorção do observador é de tamanha força que ele parece esquecer de seu corpo e não se lembra que lhe é permitido fazer uso do seu aparelho vocal. O que as análises de Hansen deixam passar é que, mais do que permitir uma percepção e atuação corporal alinhada com a integração entre mente e corpo, tal como propõem as ciências cognitivas das quais suas teorias são tributárias, Place Ruhr faz toda a ação corporal centrar-se no aprimoramento de uma experiência visual. Em contraposição a este modelo, uma verdadeira investida no engajamento corporal do público estaria, portanto, diametralmente oposta ao deslocamento transcendente do sujeito para o espaço virtualizado.

\section{O ciberplatonismo}

Place Ruhr e outros trabalhos na linha floating work of art, tais como Virtuelle Welten (1992), de Peter Weibel, Crossings (1995), de Stacey Spiegel e Rodney Hoinkes, e T_Visionarium (2009), de Dennis Del Favero, Jeffrey Shaw, Neil Brown, Peter Weibel e Matt McGinity, mantêm, assim, relações íntimas com o modelo da caverna de Platão. Eles propõem um mundo idealizado e formalizado pela mente, que transcende a fisicalidade e avança rumo a um universo que se esconde do "lado de lá" da experiência corporal.

Assim como elas, grande parte das abordagens do ciberespaço e dos ambientes virtuais mantêm relações estreitas com o que Giselle Beiguelman (2005) chamou de (ciber)neoplatonismo e visam aprimorar ainda mais as técnicas de absorção do sujeito, tal como fica evidente na abordagem do artista e teórico alemão Peter Weibel.

O cinema do futuro poderá simular ou estimular precisamente essas redes nervosas baseadas no impulso. No lugar do trompe 
l'oeil, o próximo passo poderia ser o trompe le cerveau - o aparelho cinematográfico enganará o cérebro, não o olho, dirigindo e controlando redes nervosas com precisão e com o apoio de máquinas moleculares. Poderíamos, então, imitar a visão, construir uma experiência cinemática sem luz nem olhos, criar imagens sem percepção, trasladadas mediante a estimulação direta de redes nervosas. Graças a códigos temporais, baseados em impulsos que estimulem diretamente o cérebro, com ajuda de neurochips ou chips cerebrais, haveria percepção sem os sentidos, enxergar-se-ia sem ter que usar os olhos. A estimulação - a representação artificial do mundo baseada em pulsações - substituiria a simulação. O cérebro, em oposição ao olho, se converteria em monitor ${ }^{7}$ (WEIBEL, 2004, p.79).

No modelo de mundo de Platão, o corpo "perturba a alma e a impede de conhecer a verdade". Seguindo a tradição platônica, este regime está baseado na concepção de que o corpo é um gerador de distorções e que, para ter acesso ao outro mundo, é necessário eliminar ou diminuir ao máximo grau a atuação corporal do sistema perceptivo. É justamente de acordo com este modelo que Peter Weibel concebeu sua proposta utópica de cinema do futuro: o neurocinema. Para Beiguelmam (2005), no entanto, se Platão usa a imagem do corpo como sendo uma prisão da alma, Weibel usa a mesma metáfora para pregar o "mundo virtual" como libertação, para o humano, de sua vida, do seu corpo, do tempo e do espaço que o prenderiam.

A vocação platônica de tais ambientes se deixa ver então na dualidade imposta entre os mundos real e virtual, entre o material e o imaterial, entre corpo e mente, entre experiência sensível e idéia. A estratégia narrativa nesses ambientes é motivada pela negação da idéia da "representação da realidade". Assumindo o modelo narrativo de James Joyce, estas obras visam, sobretudo, "gerar realidades" a serem exploradas pelo sujeito. Este conjunto de obras compõe assim um inventário de mundos gerados por tais dispositivos.

Se estes ambientes virtuais forem analisados a partir da filosofia dos aparatos de Vilém Flusser (2002 e 2008), será possível concluir que, tanto quanto a estrutura não-linear da narrativa pós-moderna antecipada por Joyce, todo aparato tecnológico empregado para a construção dos ambientes imersivos geram fenômenos que se projetam a nós como mundos experienciáveis. Ou seja, segundo o filósofo, como resultado dos processos internos de todo o aparato são projetados fenômenos, os quais se apresentam conjuntamente 
como uma multiplicidade de realidades que, juntas, compõem um super complexo sistema, que Flusser concebe como "mundo codificado". No entanto, os aparatos artísticos criados a partir do regime de absorção posicionam esses fenômenos como universos paralelos que, uma vez completos em si próprios, se desprendem do mundo da experiência cotidiana. O único ponto de contato é o observador, quando tomado como seu explorador. No entanto, esta ligação entre os dois mundos permanece fragilizada pela secção entre a operação dos comandos de navegação e uma visibilidade transcendente. Desse modo, as realidades geradas pelos aparatos de absorção estão para sempre separadas no mundo da experiência, como duas linhas paralelas que seguem sem nunca se cruzarem, de acordo com o que Leibniz concebeu como mundos incompossíveis.

Uma análise que relacione estes trabalhos com o teatro permitem concluir que, assim como o ideal de transferir o público de seu lugar na platéia para o epicentro da cena chegou a ser considerado como a própria essência do teatro (ROUBINE, 1998, p.119), segundo o que defende a maioria dos teóricos e artistas do ciberespaço e dos ambientes virtuais, seria da própria natureza dos dispositivos digitais de mediação a criação de ambientes virtuais imersivos, sendo esta uma característica irrevogável.

No entanto, é necessário questionar se os regimes de imagem baseados na absorção seriam de fato um tipo de especificidade das tecnologias digitais de mediação e se, por isso, seriam estes os modelos mais apropriados para se entender a produção baseada em tais tecnologias ou se estes regimes são mais o resultado da transferência de certos modelos mentais em vigor anteriormente, deslocados que são para os aparatos contemporâneos por artistas e teóricos.

\section{Máquinas de transcendência e a gênese do virtual}

Através das extensões das figuras pintadas no teto, 'o corpo físico' do observador alcança a 'iluminação' e é puxado para dentro do céu por uma representação artística de verticalidade até então sem precedentes (GRAU, 2003, p.48).

O sonho da imersão total do público na obra de arte ultrapassa os horizontes do cinema e talvez esteja menos relacionado à tecnologia do que às próprias pretensões da arte 
ao longo dos séculos. Para o teórico do virtual Michael Heim (1993, p.124), "Ao invés de controlar ou escapar ou entreter ou comunicar, a promessa final de VR [Realidade Virtual] pode ser [a de] transformar, resgatar nossa consciência da realidade, algo que a mais alta arte tentou fazer". Ainda na segunda metade do século XIX, ao compor Parsifal, mais do que criar uma ópera, uma música, uma peça de teatro, Richard Wagner pretendeu criar uma "obra de arte total". Segundo ele, a articulação perfeita entre visão, som, movimento e drama seria capaz de varrer o espectador para outro mundo. Wagner visava um intenso diálogo entre a obra e a realidade; e algo tão arrebatador que seria capaz de alterar a realidade habitual.

Nos caminhos do ilusionismo do século XVIII, o teatro também perseguiu o objetivo utópico de fazer o público se descolar de sua posição na plateia e imergir na história ao máximo grau. "O ideal, jamais alcançado, mas sempre pretendido, seria mesmo que o espectador confundisse a ficção do espetáculo com a realidade" (ROUBINE, 1998, p.119). Ideal este que em sua época chegou a ser considerado inerente ao próprio teatro, como também o é hoje no cinema e nos ambientes virtuais. A estratégia para isso foi a de criar um espetáculo teatral dentro de um universo próprio à cena, fingindo ignorar o olhar externo do espectador. Neste modelo de teatro, além das três paredes que compõem o palco à italiana, propõe-se que os atores em cena imaginem a existência de uma quarta parede separando a cena do seu público. Os atores fingem estarem confinados a uma caixa preta, em um mundo exclusivo a eles. Segundo a proposta de Diderot, a quarta parede faz surgir uma cena autobastante, contida em seu próprio mundo que, ignorando o olhar externo, coloca os atores em seu universo particular. A busca pela inserção total do espectador na cena também foi, provavelmente, um dos maiores motivadores do desenvolvimento técnico e estético das primeiras décadas do cinema e faz parte até hoje do modelo de representação dominante.

Na mesma época de invenção do cinema, outros dispositivos faziam sucesso experimentando técnicas de imersão capazes de transportar fisicamente o público para um universo alternativo, produzido pela mistura de imagens e de artifícios cênicos. Nesta época faziam sucesso os panoramas, como The battle of Sedan, construído por Anton von Werner, os museus de cera, como o da capital francesa, o Hale's Tour, um dispositivo criado por George Hales que projetava imagens cinematográficas nas janelas de vagões de trens, dando a impressão a quem estava dentro de que o vagão estava em movimento. 
Perseguindo o ideal da inserção completa do público na história, desde os primeiros anos, a estética cinematográfica acabou por incorporar o modelo de cena forjado a partir do palco à italiana, separando o público da representação. Como destaca Ismail Xavier, enquanto no teatro a quarta parede "protegia" a ficção da realidade, no cinema "tal aprisionamento ganha mais força, pois o espaço imaginário se projeta na pura superfície (a luz na tela)", já que não há atores nem cenário na sala de cinema. O cinema como o conhecemos hoje, com sua habilidade de nos transportar para dentro da cena, somente foi possível graças à precisão de regras rígidas que garantem a separação entre o público e o universo da ficção. Isso acontece, como já ressaltou Ismail Xavier (2003, p.18), “(...) para que a geometria da representação se preserve e a ficção se proteja do real, mantida a separação entre olhar e mundo diegético".

Mas, muito antes do realismo ilusionista do século XVIII ou do cinema, esta separação entre os mundos da representação e da observação já estava inscrita de maneira marcante na proposta do Renascimento. Desde as regras prescritas por Albertí, em seu tratado De Pictura, a pintura renascentista tomou a idéia da janela como sendo a metáfora perfeita para se compreender a imagem. Para os artistas da época, o quadro deveria tornar-se o limiar entre o espaço interno da imagem e o ponto de vista daquele que o observa.

No horizonte da utopia renascentista estava a idéia de tornar imperceptível a diferença entre uma janela e um quadro dependurado na parede, "ampliando" o espaço, adicionando-lhe novas aberturas, alterando diretamente nossa percepção espaciotemporal. Como os batentes de uma janela projetada pelo arquiteto para um edifício, tanto a boca do palco à italiana, isolada pela quarta parede, a tela do pintor renascentista, o quadro do cinema, quanto a tela do computador criam o que Anne Friedberg (2006) chamou de "corte ontológico". Segundo ela, entre o universo interno da representação e o da experiência concreta do mundo existe um corte ontológico que, ao mesmo tempo em que separa estes dois mundos de naturezas diametralmente opostas, torna-se o lugar no qual estes mundos se encontram.

Entretanto, existe aí uma diferença importante. Em uma pintura ou fotografia, o quadro é usualmente visto em um espaço bem-iluminado, de modo que suas bordas são tão significantes quanto seu centro. Enquanto que, para o espectador de cinema, o quadro desaparece completamente forçando a visão a mergulhar nas profundezas da imagem. A escuridão do 
ambiente faz com que a luz vinda da tela tanto dilua as bordas quanto chame o espectador para dentro de si. Se, por um lado, a transparência do quadro cinematográfico facilita o efeito de imersão, por outro, ele torna ainda mais intenso o regime de absorção da imagem que visa, em última instância, à separação entre ficção e realidade, entre o mundo físico e o mundo visual.

\section{O mergulho no universo informacional}

A busca pela absorção completa em mundos alternativos ganhou outros contornos no campo das tecnologias digitais de mediação. Nas últimas décadas, os ambientes virtuais atualizaram este modelo de representação com tamanha força que, até bem pouco tempo atrás, este parecia ser um modelo definitivamente insuperável. Ambientes virtuais ou mundos virtuais são duas definições genéricas muito utilizadas quando se faz referência a um conjunto de técnicas de construção de mundos ficcionais e de imersão baseadas em tecnologias digitais específicas, como as de realidade virtual, cave, ou mesmo panoramas digitais. Em alguns casos, no entanto, este termo é utilizado também para se referir a projetos hospedados na web.

Entretanto, tentar entender estes ambientes a partir de termos como realidade virtual, ambientes virtuais ou mundos virtuais pode causar mais confusão do que revelar sua verdadeira estrutura interna. Isso porque a própria idéia de virtual não se refere especificamente a uma técnica, método ou dimensão de realidade, mas a um estado de existência em potencial. O virtual é aquele que existe apenas como possível, que se encontra em estado potencial, que tende à atualização, mas que ainda não se concretizou ou se formalizou. Pierre Lévy afirma que a árvore está virtualmente presente na semente e, retomando Aristóteles, ele afirma: "Em termos rigorosamente filosóficos, o virtual não se opõe ao real, mas ao atual: virtualidade e atualidade são apenas duas diferentes maneiras de ser" (LÉVY, 1996, p.15).

Por isso, os termos utilizados para designar estes regimes de sentido, muitas vezes, aparecem mais como um tipo de slogan de determinada tecnologia ou ideologia do que como um conceito verdadeiramente estruturado. Ao contrário do que alguns teóricos propõem, pensar em uma arte do virtual ou uma poética do virtual não seria a construção de espaços de ilusão ou de mundos alternativos, mas a elaboração de obras que permitissem ao público e ao artista, justamente, a operação 
em relação às potencialidades da automatização que estariam disponíveis em estado de possibilidade na obra, como o fazem muitos dos projetos empreendidos no campo das artes cibernéticas e da bioarte, por exemplo.

Colocando de lado as questões relativas à ambiguidade inerente à terminologia em questão, para compreender os ambientes virtuais é necessário seguir novos rumos. Michel Heim propôs oportunamente uma ontologia de tais ambientes identificando entre os pioneiros dessas técnicas os principais vetores conceituais que guiaram a criação dos atuais aparatos imersivos. Para tanto, Heim foi buscar os precedentes abertos pelo célebre romance de Willian Gibson e, especialmente, pelo Holodeck, do seriado Star Trek: The Next Generation, este que se tornou um tipo de arquétipo inalcançável para os ambientes virtuais.

Desde o início, as pesquisas técnicas para o desenvolvimento de ambientes virtuais mantinham no seu horizonte a promessa de amplificar ainda mais a capacidade de imersão gerada pelo cinema. Talvez por isso, até hoje estes ambientes mantenham com o cinema tão grande proximidade, pelo menos no que se refere à busca pela imersão total do espectador. Enquanto no cinema a imagem se apresenta como uma passagem que dá acesso ao olhar do visitante, que é conduzido através do espaço interno da representação, nos ambientes virtuais, a imagem torna-se um espaço a ser explorado pelo olhar do participante, que passa a conduzir seu próprio percurso. Esta situação explica como não é por acaso que, assim como as teorias da enunciação cinematográfica foram importantes para compreender o cinema, as atuais teorias do virtual ganharam credibilidade para explicar a situação atual da imagem digital. Nos dois casos, a tela "torna-se o limiar de tensões entre a imobilidade do espectador e a mobilidade das imagens vistas através das janelas mediadoras do filme, televisão e monitor de computador"8 (FRIEDBERG, 2006).

Por outro lado, o palco do teatro ilusionista realista é também atualizado pelos mundos virtuais (LAUREL, 1993, p.17), que se tornam habitados tanto por agentes humanos, como por seres e objetos autômatos do contexto da representação. Conforme notou Janet Murray, o modelo herdado do teatro coloca a tela do computador no lugar da "quarta parede" do palco italiano, enquanto o teclado, o mouse e o joystick convertem-se em objetos limiares que habilitam para o percurso no interior desse universo. Tais estratégias, segundo a pesquisadora, visam elaborar a experiência da obra tal qual uma visita (MURRAY, 2003). 
Assim, a idéia de ambiente virtual - que permeia obras de realidade virtual, caves e panoramas - está profundamente ligada a um regime de sentido que visa em última instância à absorção do sujeito para dentro da imagem. Nos regimes de absorção, conforme o conceito aqui proposto, quem se lança à experiência é instantaneamente arrebatado pelo dispositivo e extasiado pelo prazer de explorar um mundo outro que a ele se abre. As bases estéticas e epistemológicas implicadas em tais obras têm, como característica fundamental, a capacidade de completa absorção do sujeito pela imagem, que o arrasta para dentro de si de modo a fazê-lo perambular em meio a seus labirintos. A absorção pode então ser definida como um regime de sentido que arrebata o sujeito de seu mundo, que o aparta da sua realidade subjetiva e coletiva, mantendo sua mente absorta no encantamento de um mundo paralelo criado pela imagem.

Assim definido, o modelo de conhecimento implicado em regimes de sentido fundados na absorção alinha-se em um vigoroso neoplatonismo, ampliado vertiginosamente pela base das tecnologias digitais. Em sua Alegoria da Caverna, livro V de $A$ República, Platão constrói um modelo mental para se pensar a condição do homem em relação ao mundo, separando o domínio das coisas sensíveis do mundo das idéias. Platão separa o mundo das idéias e formas perfeitas - por ele entendido como realidade - do mundo enganoso das coisas sensíveis. A alegoria platônica é uma metáfora que pretende demonstrar como as aparências do mundo escondem sua verdade e como a experiência do corpo é incapaz de dar acesso à verdade do mundo das idéias.

Não foram poucos os teóricos que analisaram o cinema e a fotografia a partir da matriz platônica. Edgar Morin (1956) compara a caverna à câmara obscura para analisar a fotografia. Na década de 1970, os teóricos do dispositivo partiram da caverna platônica para explicar o que descreveram como a situação de aprisionamento do espectador cinematográfico. Por outro lado, a alegoria platônica tem sido o ponto de partida para muitas filosofias e teorias que se engajaram em uma verdadeira cruzada contra as imagens, sob o pretexto de que elas estariam nos afastando da autêntica realidade.

Mais recentemente, nas últimas duas décadas, o modelo platônico tem servido como inspiração para muitos artistas elaborarem imagens altamente imersivas e tecnologias capazes de absorver cada vez mais profundamente seu público no mundo das imagens virtuais. Como aponta Heim, nos regimes em vigor, o sujeito interfaceado pelos fluxos de entrada e saída 
de dados perde-se em um mundo que se abre ao seu espírito. Ele torna-se suspenso no espaço do computador, deixando seu corpo para imergir no mundo digital de sensações. Mas, no ciberneoplatonismo, ao invés de imergir em um mundo platônico dos sólidos perfeitos e dos números ideais, o sujeito mergulha na forma de dados, na informação, que a sua vez passa a herdar a beleza platônica. Ironicamente, ao tentar nos retirar do aprisionamento da enganadora experiência concreta, esses mundos acabam nos lançando em novas cavernas.

Assim como o Holodeck de Star Trek, o sonho do mergulho total em um mundo simulado tem permanecido no horizonte da ficção científica. Em 1999 dois filmes emblemáticos tematizaram a questão: Matrix, dos irmãos Larry e Andy Wachowski, e Existenz, de David Cronenberg. Diferentemente da divisão clara que separa os lados de dentro e de fora da "caverna" de Matrix, o filme de Cronenberg confere mais ambigüidade à questão. Em Existenz não há uma oposição clara entre um lado e outro; ao invés disso, as personagens passam a todo o momento por diferentes estados de realidade, sendo impossível saber onde começam e onde acabam as barreiras que separam um mundo do outro ou mesmo eleger uma camada como "a verdadeira" realidade.

Umas das principais questões levantadas por Cronenberg é a relação entre os habitantes do jogo e os seus corpos e lugares físicos. A todo o momento as personagens se queixam por sentirem-se "desencorporadas" e testam seus sentidos através do tato, do cheiro, buscando o próprio corpo na tentativa de estabelecer uma matriz física de re-incorporações. Se, por um lado, eles se preocupam em saber como estarão seus corpos biológicos na realidade física que eles acreditam existir, por outro, eles são incapazes de dizer ao certo se é mesmo nesta realidade física que eles se encontram, por serem incapazes de perceber seu corpo. Sua condição de constante atravessamento entre realidades possíveis não lhes permite saber se existe de fato uma realidade primeira, na qual suas mentes poderiam finalmente "encontrar seus corpos". Esta ambiguidade que se abre a partir do filme de Cronenberg nos leva ao questionamento sobre a possibilidade de se pensar em um modelo de virtualidade que não fosse fundado em mundos paralelos.

Torna-se, assim, importante questionar se seria possível conceber um tipo de imagem que não estivesse do "lado de lá", mas que fosse capaz de se lançar rumo ao mundo da experiência e que formasse com este uma só realidade, de ordem complexa e sistêmica. 


\section{Rumo a outras imagens}

No campo das ciências, as pesquisas mais recentes da neurociência e da inteligência artificial oferecem modelos que colocam em crise o dualismo entre a mente e o corpo proposto por Platão e levado à frente por outros filósofos - Descartes; Hegel - e que tanto marcaram a maneira como o homem entende o mundo. Também o dualismo entre matéria e energia passou a ser questionado a partir das propostas einsteinianas.

Uma pista importante para responder a esta pergunta sobre a natureza da imagem pode ser encontrada em outras áreas de atuação artística, ao lembrar que, desde o final do século XIX, o teatro e outras áreas artísticas buscam por outros regimes de sentido, de caráter não absortivo. Após a primeira grande guerra, os acontecimentos sociais e políticos engendraram novos rumos para as artes, o que fez surgir uma nova estética. No teatro, pode-se creditar a Brecht a ruptura da quarta parede quando ele põe em cena seu teatro épico, teoria que sugere ver o teatro não mais como ilusionismo ou entretenimento, mas sim como indicador de novos sentidos. Brecht afirmava que seu teatro deveria incomodar e não acomodar o espectador na poltrona.

Mais adiante, o espaço de representação cênica foi fundido com o espaço quotidiano nos happenings dos anos 1960 e nas performances da década de 1970. No campo das imagens técnicas, esta separação marcante no cinema clássico foi colocada em cheque pelos artistas do vídeo, que investiram em diferentes técnicas para questionar o distanciamento do sujeito com o espaço da representação. Por outro lado, ainda antes disso tudo, a janela renascentista foi banida pelo barroco que fazia da pintura a própria extensão dos espaços arquitetônicos, tomando os visitantes das igrejas pelo seu próprio corpo físico e misturando-o com anjos e demônios pintados e esculpidos no ambiente.

Também nas artes plásticas, a maior parte dos movimentos modernos rompeu com as heranças do classisismo procurando imagens que não fossem "reflexos do real". Assim como ocorreu com a pintura, o teatro e o vídeo, as artes baseadas em tecnologias digitais começam a apontar com consistência para o rompimento com os paradigmas dos regimes de absorção para investir em outras propostas de representação.

No horizonte da computação ubíqua, roupas, objetos, corpos e espaços passam a incorporar microcontroladores, sensores, conexões em rede, telas e projetores. Com isso, tudo que nos cerca se transforma em plataforma eletrônica para imagens, 
sons e textos, colocando-nos, assim, no alvorecer do que se poderia conceber como "ubiquidade tecnomidiática", uma condição cultural que transforma tudo a nossa volta, inclusive nós mesmos, em um meio tecnológico de produção e circulação imagética. No cenário que se ergue a partir de agora, a imagem digital deixa de se apresentar como espaços paralelos e passa a ser inserida de maneira inédita em objetos e cenários que fazem parte da nossa vivência concreta do mundo, tais como eletrodomésticos, móveis, ambientes domésticos e espaços públicos.

Neste mesmo tempo, uma parte cada vez maior da produção artística contemporânea avança rumo a outros regimes de sentido, alavancada por diversos deslocamentos nos processos de significação em questão. Ao atentar para a produção em campos como os das instalações interativas não imersivas, das artes cibernéticas, da realidade misturada, da locative media, das intervenções urbanas, do site-specific é possível identificar indícios da emergência outros regimes de sentido que se opõem consistentemente ao dos ambientes imersivos.

Estas novas imagens oferecem indícios suficientes para questionar se o fato dos regimes de absorção terem sido a base fundadora de parte significativa da produção e das teorias dos aparatos digitais desde o seu surgimento não se deve, na verdade, a fácil incorporação dos pensamentos que se ergueram em torno da pintura, da fotografia, do teatro e, principalmente, do cinema pelos artistas e teóricos que se dedicam a este campo de práticas. Analisar estas novas imagens, portanto, é uma tarefa que demanda um deslocamento também epistemológico por parte do pesquisador e do criador. Uma investida nesta direção foi ensaiada na filosofia por Vilém Flusser, por meio da sua concepção de imagem como projeto9 ${ }^{9}$ De fato, um dos problemas cruciais para esta proposição conceitual é justamente escapar da força da fortuna crítica acumulada sob os domínios dos regimes de absorção. Entretanto, futuras análises que visem compreender esta passagem nos regimes de imagem a partir destes dispositivos emergentes serão determinantes para perceber as articulações em curso na cultura visual (e corporal) contemporânea.

\section{Referências}

ANDERS, Peter. Toward an architecture of mind. In CAiiA-STAR Symposium: Extreme parameters. New dimensions of interactivity, 2001. Disponível em: http://www.uoc. 
edu/artnodes/espai/eng/art/anderso302/anderso302.html Acesso em 31 de janeiro de 2010.

. Ciberespaço antrópico: definição do espaço eletrônico. In: DOMINGUES, Diana. Arte e vida no século XXI. Sp: Unesp, 2003.

AUMONT, Jacques. $O$ cinema e a encenação; tradução Pedro Elói Duarte. Lisboa: Edições Texto \& Grafia, 2008.

AUMONT, Jacques e outros. A estética do filme; tradução Marina Appenzeller. Campinas: Papirus, 1995 (Coleção Ofício das Artes).

AZUMA, R. et al. Recent Advances in Augmented Reality. IEEE Computer Graphics and Applications. 2001, v .21, n.6, p. 34-47.

BAITELLO Junior, Norval. A era da iconofagia. Ensaios de comunicação e cultura. São Paulo: Hacker Editores, 2005. . A escalada da abstração In: O universo das imagens técnicas: elogio da superficialidade. São Paulo: Annablume, 2008 (prefácio).

BAKHTIN, Mikhail. Estética da criação verbal; trad. Maria Ermantina Galvao G. Pereira. São Paulo: Martins Fontes, 2000. BALÁZ, Bela. Nós estamos no filme. In: XAVIER, Ismail (org.). A experiência do cinema. Rio de Janeiro: Edições Graal, 1983.

BAUDRY, Jean-Louis. Efeitos ideológicos produzidos pelo aparelho de base. In. XAVIER, Ismail (org.). A experiência do cinema. Rio de Janeiro: Edições Graal, 1983.

BEIGUELMAN, Giselle. O Platão que existe em Weibel. Disponível em http://netart.incubadora.fapesp.br. 2005. Acesso em dezembro de 2010.

BENVENISTE, Émile. Problemas de lingüística geral I. Trad. de Maria da G. Novak e Maria L. Neri. Campinas-SP.: Pontes, $4^{\text {a }}$ ed., 1995.

BETTETINI, Gianfranco. The language and techinique of the film. Haia: Mouton, 1973.

CASETTI, Francesco. D'un regard l'autre, le film et son spectateur, 1990.

CRARY, Jonathan. Techniques of the Observer. Cambridge: The MIT Press, 1991.

DINKLA, Söke. The art of narrative: towards the floating work of art. In. RIESER, Mark, ZAPP, Andrea (ed.). New screen media: cinema/art/narrative. Londres: BFI Publishing, 2002. DOMINGUES, Diana. (org.) A arte no século XXI: a humanização das tecnologias. São Paulo: Fundação Editora da UNESP, 1997. 
DUBOIS, Philippe. Cinema, video, Godard. Tradução de Mateus Araújo Silva. São Paulo: Cosac Naify, 2004. (Coleção cinema, teatro e modernidade).

FLUSSER, Vilém. We shall survive in the memory of others. Budapest: $C_{3}$ Center for Culture and Communication Foundation, 2010 (DVD).

. O universo das imagens técnicas: elogio da superficialidade. São Paulo: Annablume, 2008.

Filosofia da caixa preta: ensaios para uma futura filosofia da fotografia. Rio de Janeiro: Relume Dumará, 2002. . Los Gestos. Barcelona: Herder, 1994.

FOUCAULT, Michel. As palavas e as coisas: uma arqueologia das ciências humanas; tradução Salma Tannus Muchail. São Paulo: Martins Fontes, 2002.

FRIEDBERG, Anne. The Virtual Window: From Alberti to Microsoft. The MIT Press, 2006

. The Virtual Window Interactive. Website. Disponível em: $h t t p: / / t h e v i r t u a l w i n d o w . n e t /$. Acesso em maio de 2010.

GIANNETTI, Claudia. Estética digital: sintopía del arte, la ciencia y la tecnología. Barcelona: L’Angelot, 2002.

GOLDBERG, Roselee. Performance art: from futurism to the present. $2^{\mathrm{a}}$ edição. Cingapura: Thames and Hudson, 2001.

GREINER, Christine. O corpo: Pistas para estudos indisciplinares. São Paulo: Annablume, 2005.

GRAU, Oliver. Virtual art: from illusion to immersion. Cambridge: MIT, 2003.

HANSEN, Mark B. N. Bodies in Code: Interfaces with Digital Media. London: Routledge, 2006.

. New philosophy for new media. Cambridge e Londres: MIT Press, 2004.

HEIM, Michael. The Metaphisics of Virtual Realiy. New York: Oxford University Press, 1993.

KANT, Immanuel. Crítica da Razão Pura. Lisboa: Calouste Gulbenkian, 1994.

KIRNER, Claudio e TORI, Romero. Fundamentos de Realidade Aumentada. In: TORI, Romero, KIRNER Claudio e SISCOUTO, Robson (Org.). Fundamentos e Tecnologia de Realidade Virtual e Aumentada. Porto Alegre: Sociedade Brasileira de Computação - SBC, 2006, v. 1, p. 23-37.

KRUEGER, Myron. Myron Krueger Live. Ctheory.net. Artigo A104. 2002. Disponível em: http://www.ctheory.net/articles.aspx?id=328. Acesso em 31 de outubro de 2010 (entrevista concedida à Jeremy Turner). 
LANDOW, George P. Hyper text theory. Baltimore, Mariland: The Jhons Hopkins University Press, 1994.

Hypertext: the convergence of contemporary critical theory and tchnology. Baltimore: Jhons Hopkins U. Press, 1992.

LAUREL, Brenda. Computer as theater. Boston: AddisonWesley, 1993.

LEÃO, Lucia. O Labirinto da Hipermídia. São Paulo: Iluminuras, 2005b.

LEMOS, André. Mídias Locativas e Territórios Informacionais. In Santaella, L., Arantes, P. (ed), Estéticas Tecnológicas: Novos Modos de Sentir. SP: EDUC. pp. 207-230, 2007.

LÉVY, Pierre. O que é o virtual? Tradução de Paulo Neves. São Paulo, 1996.

MACHADO, Arlindo. O sujeito na tela: modos de enunciação no cinema e no ciberespaço. São Paulo: Paulus, 2007.

MANOVICH, Lev. New media: from Borges to HTML. www.manovich.net/docs/manovich_new_media.doc,2002. (12/10/2006)

MARTIN, Marcel. A linguagem cinematográfica; tradução Paulo Neves; revisão técnica Sheila Schvartman. São Paulo: Ed. Brasiliense, 2003.

MILGRAN, Paul e KISHINO, Fumio. A Taxonomy of Mixed Reality Visual Displays In IEICE Transactions on Information Systems , E77-D. 1994. Disposnível em: http://etclab. mie.utoronto.ca/people/paul_dir/IEICE94/ieice.html). Acesso em novembro de 2009.

MITCHELL, William. The reconfigured eye: visual truth in the post-photographyc era. Cambridge: The MIT Press, 1998.

MORIN, Edgar. Le Cinéma ou l'Homme Imaginaire. Paris: Minuit, 1956.

MULVEY, Laura. Prazer visual e cinema narrativo. In. XAVIER, Ismail (org.). A experiência do cinema. Rio de Janeiro: Edições Graal, 1983.

MURRAY, Janet Horowitz. Hamlet no holodeck: o futuro da narrativa no ciberespaço. Tadução: Elissa Khoury Daher, Marcelo Fernandez Cuzziol. São Paulo: UNESP Itau Cultural, 2003. PARENTE, André. A forma cinema: variações e rupturas. In. MACIEL, Katia (org.). Transcinemas. Rio de Janeiro: Contra Capa Livraria, 2009 (Coleção N-Imagem)

PAUL, Christiane. L'art numérique. Paris: Thames \& Hudson, 2004.

PLAZA, Julio. Arte e Interatividade: autor-obra-recepção. Revista de Pós-graduação, CPG, Instituto de Artes, Unicamp, 
20oo. Disponível em: http://www.iar.unicamp.br/disciplinas/ap858/AXILA/pagarlindomachado.html Acesso em 31 de maio de 2008.

POSTER, Mark. The second age media, Cambridge, Polity Press, 1995.

RIESER, Mark, ZAPP, Andrea (ed.). New screen media: cinema/art/narrative. Londres: BFI Publishing, 2002.

ROUBINE, Jean-Jacques. A linguagem da encenação teatral 1890-1990. Rio de Janeiro: Jorge Zahar, 1982.

RYAN, Marie-Laure. La narración como realidad virtual: la inmersión y la interactividad en la literatura y en los medios electrónicos. Barcelona: Paidós, 2004.

. Avatar of story. Minneapolis: University of Minnesota Press, 2006.

SHAW, Jeffrey. Movies after film: the digitally expanded cinema. In. RIESER, Mark, ZAPP, Andrea (ed.). New screen media: cinema/art/narrative. Londres: BFI Publishing, 2002.

SHAW, Jeffrey \& WEIBEL, Peter (ed). Future Cinema: the cinematic imaginary after film. Cambridge: MIT, 2003.

WEIBEL, Peter. La imagem inteligente: ¿neurocinema o cinema cuántico? In: Arte Algorítmico. De Cezane a la Computadora. Seminário organizado por UNESCO y MECAD/ ESDi, 2004.

WEISER, Mark. Some computer science issues in ubiquitous computing. Communications of the ACM. 1993, 36 (7): 75-84. XAVIER, Ismail. O olhar e a cena. São Paulo: Cosac\&Naify, 2003.

\section{NOTAS}

1. Ainda hoje se mantém o debate sobre a veracidade do episódio reportado pelo jornal da capital francesa, o qual publicou a matéria afirmando que as pessoas sentadas em suas poltronas, ao verem a imagem do trem vindo em sua direção, saíram correndo, abandonando a sala de exibição. O fato é que, tendo ou não ocorrido este fato, simplesmente o existir da matéria e da conotação mitológica do acontecimento demonstram como a sensibilidade da época foi abarcada pelo cinema.

2. Tradução livre do original: "The floating work of art conceives of the digital medium, not as an extension of the human sensory organs, but as an aesthetic space, which allows for the reconstruction of a changed world order."

3. O termo dispositivo é utilizado aqui a partir da concepção de dispositivo cinematográfico de Jean-Louis Baudry (1983). Por vezes, é realizada uma extrapolação deste conceito para o contexto dos ambientes imersivos para fazer referência ao conjunto de técnicas e tecnologias envolvidas para a produção destes ambientes, em suas dimensões materiais e imateriais.

4. As teorias do cinema apropriam-se das teorias da enunciação da linguística. Para mais, ver Bakhtin (2000) e Benveniste (1995). 
5. Tradução livre do original: “(...) a shift from a dominant ocularcentrist aesthetic to a hapitc aesthetic rooted in embodied affectivity."

6. Tradução livre do original: “(...) Place Ruhr forces them [the viewer] to abandon their bodily relation to the surrounding real space and enter the fictional space that the work offers(...)."

7. Tradução livre do original: "El cinema del futuro podrá simular o estimular precisamente esas redes nerviosas basadas en el impulso. En lugar del trompe loeil, el próximo paso podría ser el trompe le cerveau -el aparato cinematográfico engañará al cerebro, no al ojo, dirigiendo y controlando redes nerviosas con precisión y con el apoyo de máquinas moleculares. Podríamos entonces imitar la visión, construir una experiencia cinemática sin luz ni ojos, crear imágenes sin percepción, trasladadas mediante la estimulación directa de redes nerviosas. Gracias a códigos temporales, basados en impulsos que estimulan directamente el cerebro, con ayuda de neurochips o chips cerebrales, habría percepción sin los sentidos, se vería sin tener que usar los ojos. La estimulación -la representación artificial del mundo basada en pulsaciones- sustituiría la simulación. El cerebro, en oposición al ojo, se convertiría en la pantalla".

8. Website, disponível em: http://thevirtualwindow.net/

9. A concepção de imagem como projeto foi levada à diante na tese de doudorado defendida por este autor na busca de uma análise abrangente dos regimes de imagem em interfaces interativas em realidade aumentada, arte cibernética e videoinstalações intertativas.

Recebido em: 10/03/14

Aceito em: 30/03/14

\section{CESAR BAIO}

baio.cesar@gmail.com

Mestre e doutor em Comunicação e Semiótica pela PUC/SP, Cesar Baio realizou estágio sanduíche na Universität der Künste Berlin (UDK).

Atualmente é professor adjunto da Universidade Federal do Ceará. Sua pesquisa está voltada para a imagem técnica e os aparatos tecnológicos de mediação na arte. Seu trabalho tem sido elaborado crítica e poeticamente por meio de ensaios teóricos e trabalhos artísticos. 